\title{
Impact of metformin on peak aerobic capacity
}

\author{
Barry Braun, Pamela Eze, Brooke R. Stephens, Todd A. Hagobian, \\ Carrie G. Sharoff, Stuart R. Chipkin, and Benjamin Goldstein
}

\begin{abstract}
Individually, exercise and the drug metformin have been shown to prevent or delay type 2 diabetes. Metformin mildly inhibits complex I of the electron transport system and may impact aerobic capacity in people exercising while taking metformin. The purpose of the study was to evaluate the effects of metformin on maximal aerobic capacity in healthy individuals without mitochondrial dysfunction. Seventeen healthy, normal-weight men $(n=11)$ and women $(n=6)$ participated in a double-blind, placebo-controlled, cross-over design. Peak aerobic capacity was measured twice using a continuous, incrementally graded protocol; once after 7-9 d of metformin (final dose $=2000 \mathrm{mg} / \mathrm{d}$ ) and once with placebo, with 1 week between tests. The order of the conditions was counterbalanced. Peak oxygen uptake $\left(V \mathrm{O}_{2}\right.$ peak $)$, heart rate (HR), ventilation $(V E)$, respiratory exchange ratio (RER), rating of perceived exertion (RPE), and test duration were compared across conditions using paired $t$ tests with the $\mathrm{R}$ statistical program. $\mathrm{VO}_{2}$ peak $(-2.7 \%)$, peak heart rate $(-2.0 \%)$, peak ventilation $(-6.2 \%)$, peak RER $(-3.0 \%)$, and exercise duration $(-4.1 \%)$ were all reduced slightly, but significantly, with metformin (all $p<0.05$ ). There was no effect of metformin on RPE or ventilatory breakpoint. Correlations between the decrement in $V_{2}$ peak and any of the other outcome variables were weak $\left(r^{2}<0.20\right)$ and not significant. Shortterm treatment with metformin has statistically significant, but physiologically subtle, effects that reduce key outcomes related to maximal exercise capacity. Whether this small but consistent effect is manifested in people with insulin resistance or diabetes who already have some degree of mitochondrial dysfunction remains to be determined.
\end{abstract}

Key words: pre-diabetes, type 2 diabetes, exercise, biguanide.

Résumé : Isolément, l'exercice physique et un médicament, la metformine, préviennent ou retardent l'apparition du diabète de type 2 . La metformine inhibe légèrement le complexe I de la chaîne respiratoire et peut avoir un effet sur la capacité aérobie des individus qui font de l'exercice physique. Le but de cette étude est d'évaluer l'effet de la metformine sur la puissance aérobie maximale d'individus en bonne santé et sans troubles mitochondriaux. Six femmes et 11 hommes en bonne santé et de poids normal participent à une étude expérimentale à double insu avec groupe témoin et inversion des groupes. On mesure deux fois la puissance aérobie de pointe au moyen d'un test d'effort continu d'intensité croissante, une fois après 7 à 9 jours de consommation de metformine (dose terminale, $2000 \mathrm{mg}$ par jour) et l'autre fois, à sept jours d'écart, après avoir pris un placebo. L'ordre des séances d'évaluation est contrebalancé. Au moyen du programme d'analyse statistique $\mathrm{R}$, on compare par des tests $\mathrm{t}$ pour mesures appariées les variables suivantes observées dans les deux conditions : la consommation d'oxygène $\left(V_{2}\right)$ de pointe, la fréquence cardiaque (HR), le débit ventilatoire (VE), le ratio d'échanges gazeux (RER), la perception de l'intensité de l'effort (RPE) et la durée du test. La metformine suscite des diminutions légères mais significatives $(p<0,05)$ des variables suivantes : le $V_{2}$ de pointe $(-2,7 \%)$, la fréquence cardiaque de pointe $(-2,0 \%)$, le débit ventilatoire de pointe $(-6,2 \%)$, le RER de pointe $(-3,0 \%)$ et la durée du test $(-4,1 \%)$. La metformine n'au aucun effet sur la RPE et sur le seuil ventilatoire. La corrélation entre la diminution du $V \mathrm{O}_{2}$ de pointe et n'importe laquelle des autres variables est faible et non significative $\left(r^{2}<0,20\right)$. L'administration à court terme de la metformine suscite des effets significatifs, mais faibles sur les variables associées à la capacité d'effort aérobie. Il reste à déterminer si ces effets manifestes quoique faibles s'observent chez des individus insulinorésistants ou souffrant du diabète, mais qui ont des troubles mitochondriaux.

Mots-clés : prédiabète, diabète de type 2, exercice physique, biguanide.

[Traduit par la Rédaction]

\section{Introduction}

The results from the Diabetes Prevention Program (DPP)

Received 8 June 2007. Accepted 20 September 2007. Published on the NRC Research Press Web site at apnm.nrc.ca on 10 January 2008.

\section{B. Braun, ${ }^{1}$ P. Eze, B.R. Stephens, T.A. Hagobian,}

C.G. Sharoff, S.R. Chipkin, and B. Goldstein. Energy

Metabolism Laboratory, Department of Kinesiology, School of

Public Health and Health Sciences, 107 Totman Building,

University of Massachusetts, Amherst, MA 01003, USA.

${ }^{1}$ Corresponding author (e-mail: bbraun@kin.umass.edu). and other similar interventions show that lifestyle intervention (i.e., modification of diet and physical activity) is remarkably effective in preventing and (or) delaying the transition from insulin resistance to diabetes. (Knowler et al. 2002; Orchard et al. 2005; Pan et al. 1997; Tuomilehto et al. 2001). In response, a tremendous effort is being made to increase participation in physical activity among overweight, sedentary individuals (Bethel and Califf 2007; Dasgupta et al. 2006; Hamman et al. 2006; Kriska et al. 2006; Manson and Spelsberg 1994). The DPP also showed that the commonly prescribed biguanide drug metformin also significantly delayed or prevented the transition from impaired glucose metabolism to a diagnosis of diabetes 
(Knowler et al. 2002; Orchard et al. 2005). In addition to being one of the most commonly prescribed drugs to treat individuals with overt diabetes, metformin is also increasingly prescribed before the diagnosis of diabetes to forestall the transition to diabetes in high-risk individuals (Anderson 2005; De Lusignan et al. 2005; Matthaei et al. 2000). Individuals prescribed metformin are also encouraged to be physically active. For many overweight or obese men and women, the additive effects of increased physical activity and metformin can be viewed as a promising combination therapy.

Several in vitro studies have shown that metformin has an inhibitory effect on the activity of complex I (transfer of electrons from NADH to coenzyme $\mathrm{Q}_{10}$ ) of the mitochondrial electron transport system (Batandier et al. 2006; El-Mir et al. 2000; Guigas et al. 2004; Leverve et al. 2003; Owen et al. 2000). Inhibition of complex I may slow the transfer of reducing equivalents from the tricarboxylic acid cycle and potentially limit the capacity for oxidative metabolism (although there is some reserve mitochondrial capacity to use oxygen during exercise with large muscle groups). If the inhibition of complex I exceeds that extra capacity, the practical implication would be a lowering of maximal cardiorespiratory capacity and increased relative intensity at any given absolute exercise workload. Perception of effort would be increased; potentially affecting exercise intensity, duration, total energy expenditure, and behavior. In studies of aerobic exercise physiology or behavior, the exercise intensity is almost always controlled by scaling it as a percentage of maximal aerobic capacity (Braun et al. 2004; Goodpaster et al. 2002; Houmard et al. 2004; Musi and Goodyear 2006). If metformin treatment lowers peak oxygen uptake $\left(V \mathrm{O}_{2 \text { peak }}\right)$, correct comparison of any outcome variables between the metformin and placebo groups will be confounded by the different relative exercise intensity in each condition.

Several laboratory groups are conducting research studies in which the addition of exercise to metformin therapy is being tested for efficacy in improving glucose metabolism (Hallsten et al. 2002; Smith et al. 2007; Tang and Reed 2001), as well as non-glycemic targets such as microvascular function (Jadhav et al. 2006) and cardiovascular indices in patients with HIV (Driscoll et al. 2004). The converse, whether treatment with metformin impacts exercise capacity, has not been considered in any systematic way. The question is relevant because a reduction in $V_{2}$ peak caused by metformin may affect functional exercise capacity and impact compliance with physical activity guidelines.

Therefore, it is important from both a clinical and experimental perspective to understand whether or not treatment with metformin affects exercise capacity. The purpose of the present study was to assess whether short-term treatment with the typical clinical dose of metformin impacted maximal oxygen consumption and related variables (e.g., maximal ventilation $(V E)$, heart rate $(\mathrm{HR})$, respiratory exchange ratio (RER), etc.) relative to a placebo. To understand the effects of metformin uncomplicated by the dysfunction in mitochondria or oxidative metabolism that is strongly associated with insulin resistance and type 2 diabetes (Regensteiner et al. 1998; Lowell and Shulman 2005; Ritov et al. 2005), the study was conducted in healthy people with normal glucose metabolism.

\section{Materials and methods}

\section{Overview}

The study was conducted using a longitudinal, placebocontrolled design in which subjects served as their own controls. Subjects performed a test of peak aerobic capacity twice; once while treated with metformin $(1000 \mathrm{mg}$, twice daily) and once with placebo. There were 7 days between tests to allow sufficient washout of metformin (the half-life for elimination of metformin is 2-6 h). The order in which the treatment of placebo and metformin conditions were completed was counterbalanced across subjects. $V \mathrm{O}_{2}$ peak and related variables (e.g., VE, HR, RER, etc.) were compared across the metformin and placebo conditions.

\section{Subjects}

A convenience sample of 18 locally available non-diabetic men $(n=11)$ and women $(n=7)$ participated in the study (Table 1). All subjects signed an informed consent document and completed a physical activity readiness questionnaire and a health history prior to initiating testing. All subjects were in good overall health, normal weight or overweight, but not obese (body mass index $(\mathrm{BMI})=21-29$ ), and did not use tobacco products or take any medications (e.g., other antihyperglycemic agents, statin drugs, betablockers, diuretics, etc.) or dietary supplements (e.g., chromium, vanadium, niacin, etc.) that could potentially interact with metformin and (or) maximal cardiorespiratory capacity. To maximize the generalizability of the data across fitness levels, a mix of relatively sedentary and recreationally active men and women were recruited. The study was approved by the Institutional Review Board at the University of Massachusetts (Amherst, Mass.) prior to initiation of the study. One woman dropped out of the study due to gastrointestinal problems in response to the pharmacological treatment. Therefore the final sample size consisted of 17 subjects (11 men, 6 women).

\section{Study design}

$V \mathrm{O}_{2}$ peak was determined using an incremental treadmill protocol on either a treadmill (Lifestride 9100, Life Fitness, Schiller Park, Ill.) or a cycle Ergometer (Sensormedics 800, Yorba Linda, Calif.) according to subject preference. For each individual subject, the placebo and metformin tests were always conducted at the same time of day, with no exercise for $24 \mathrm{~h}$ and no food for $3 \mathrm{~h}$ before each test. Testing commenced at a relatively easy submaximal workload that was scaled to each subject's fitness or training status (range of $50-150 \mathrm{~W}$ on the cycle ergometer and 4-6 miles/h $(1$ mile $=1.6 \mathrm{~km})$ at $0 \%$ grade on the treadmill $)$. Either the cycle resistance (25-50 W increments in early stages; $25 \mathrm{~W}$ increments as test progressed beyond first few stages) or treadmill grade $(+2 \%$ increments $)$ was increased every 2 min until a maximal voluntary effort was achieved. Respiratory gases from collected air were measured using the TrueMax2400 Metabolic Measurement System (Parvomedics, Salt Lake City, Utah). Heart rate was monitored throughout testing using a Polar Advantage Heart Rate Monitor (Polar Inc., Lake Success, N.Y.). Fifteen seconds before the end of each stage, a systemic rating of perceived exertion (RPE) was assessed by having subjects point to a num- 
Table 1. Subject characteristics $(n=17)$.

\begin{tabular}{llllll}
\hline & Age $(\mathrm{y})$ & Height $(\mathrm{cm})$ & $\begin{array}{l}\text { Body mass }(\mathrm{kg}): \\
\text { placebo }\end{array}$ & $\begin{array}{l}\text { Body mass }(\mathrm{kg}): \\
\text { metformin }\end{array}$ & BMI $\left(\mathrm{kg} \cdot \mathrm{m}^{-2}\right)$ \\
\hline Mean \pm SD & $27.9 \pm 3.3$ & $174.0 \pm 9.2$ & $71.2 \pm 15.1$ & $71.1 \pm 14.4$ & $24.1 \pm 3.6$ \\
\hline $\begin{array}{l}\text { Note: Descriptive data shown are mean and standard deviation for } 11 \\
\text { study. }\end{array}$
\end{tabular}

ber on a visual ordinal scale ranging from 6 (no exertion at all) to 20 (maximal exertion). Oxygen consumption was considered peak upon attainment of at least 2 of the following 3 criteria: increase in $\mathrm{VO}_{2}$ less than $150 \mathrm{~mL}$ despite increased workload, RER $>1.10$, and HR within 15 beats $\cdot \mathrm{min}^{-1}$ of age-predicted maximal heart rate $\left(\mathrm{HR}_{\max }=220-\right.$ age (in years)). Ventilatory breakpoint (VBP), the first inflection point at which ventilation increases more rapidly than oxygen consumption (sometimes referred to as "anaerobic threshold"), was estimated visually from the relationship between $V \mathrm{O}_{2}$ and $V \mathrm{E}$ and the relationship between $V \mathrm{CO}_{2}$ and $V \mathrm{E}$. When the two relationships are plotted on the same axes, the point at which the 2 curves reach a crossing point is defined as the VBP (BroPaitienë and Jakumaitë 2002; Cohen-Solal et al. 1991). One individual, blinded to the experimental conditions, estimated the VBP for each subject in each experimental condition.

\section{Metformin and placebo treatment}

Metformin treatment began at $500 \mathrm{mg} / \mathrm{d}$ and was increased every second day to reach the standard clinical dose, $1000 \mathrm{mg}$ twice daily. In most subjects, this dose was attained on day 5 or 6 , but in men or women who experienced gastrointestinal symptoms $(n=3)$, the ramp-up period was extended for up to 3 more days. Once attaining the final dosage, all subjects continued on that dose for 3 consecutive days. Placebo treatment was identical but all subjects were able to reach the final dose on day 5. Although it was designed to be a double-blind protocol, the presence of a metallic taste in the mouth and (or) gastrointestinal symptoms alerted several subjects (these side-effects were listed in the informed consent document as per IRB requirements) and the investigators to which treatment was being given. Despite this limitation, only a few subjects were reasonably certain which treatment they had been given and several were convinced they had metformin when they actually had the placebo.

\section{Statistical analysis}

Data are presented as condition mean, the difference between conditions, 95\% confidence interval of that difference, and exact $p$ value except where noted. Statistical significance of the differences between conditions was tested using Student's paired $t$ test. The $\alpha$ level was set at 0.05 . Correlations between outcome variables of interest were assessed using Pearson product-moment correlation.

\section{Results}

$V \mathrm{O}_{2}, \mathrm{HR}$, VE, RER, and RPE over time are shown in Figs. $1 a-1 e$ ). For the initial $11 \mathrm{~min}$ of the test, the slope of the relationships between outcome and time were virtually indistinguishable in the metformin and placebo conditions.
After this point, unequal sample sizes (due to subjects ending the test at different times in the metformin or placebo conditions) limit direct comparison by time. $V \mathrm{O}_{2}$ peak, however, whether assessed in absolute volume or scaled to body mass, was slightly $(-2.7 \%)$ but significantly lower with metformin treatment compared with placebo (Table 2). Relative to placebo, $\mathrm{VO}_{2 \max }$ on metformin was lower in 12 of 17 subjects, unchanged in 3, and higher in 2. Similarly, peak HR $(-2.0 \%), V \mathrm{E}(-6.2 \%)$, and RER $(-3.0 \%)$ were all reduced slightly in the metformin condition (Table 2). Subjects were unable to continue exercising after $13 \mathrm{~min} 56 \mathrm{~s}$ in the metformin condition compared with 14 min 31 s with placebo $(-4.1 \%)$. Nine of the 17 subjects attained a higher workload during the placebo test $(+30 \mathrm{~W}$ or $+2 \%$ grade $)$ relative to the metformin test.

Although all of the outcome variables declined significantly in the metformin condition, correlations between the change in maximal oxygen consumption and any other outcome variable were very weak with correlation coefficients all $r^{2}<0.20$ and $p>0.30$. The magnitude of the change in $V \mathrm{O}_{2 \text { peak }}$ induced by metformin was also not strongly correlated with cardiorespiratory fitness, i.e., the baseline $V \mathrm{O}_{2 \text { peak }}$ measured in millilitres per kilogram per minute $\left(\mathrm{mL} \cdot \mathrm{kg}^{-1} \cdot \mathrm{min}^{-1}\right)$. To better understand the relationships, we compared 9 metformin "responders", defined as individuals in whom $V \mathrm{O}_{2 \text { peak }}$ declined by more than $1.5 \mathrm{~mL} \cdot \mathrm{kg}^{-1} \cdot \mathrm{min}^{-1}$ (mean $\left.=-3.5 \mathrm{~mL} \cdot \mathrm{kg}^{-1} \cdot \mathrm{min}^{-1}\right)$ when taking metformin; with 6 "non-responders": defined as individuals in whom $V \mathrm{O}_{2 \text { peak }}$ declined by less than $0.5 \mathrm{~mL} \cdot \mathrm{kg}^{-1} \cdot \mathrm{min}^{-1}\left(\right.$ mean $\left.=+0.1 \mathrm{~mL} \cdot \mathrm{kg}^{-1} \cdot \mathrm{min}^{-1}\right)$ when taking metformin. There were no significant differences in the decrement in maximal HR $\left(-6.4\right.$ beats $\cdot \mathrm{min}^{-1}$ for responders vs. $\quad-5.0$ beats $\cdot \mathrm{min}^{-1}$ for non-responders), ventilation (-9.9 $\mathrm{L} \cdot \mathrm{min}^{-1}$ for responders vs. $-7.8 \mathrm{~L} \cdot \mathrm{min}^{-1}$ for nonresponders), or test duration ( $-32 \mathrm{~s}$ for responders vs. $-49 \mathrm{~s}$ for nonresponders). Similarly, of 8 subjects who reached a lower maximal workload when taking metformin, $\mathrm{VO}_{2}$ peak was lower $\left(>1.0 \mathrm{~mL} \cdot \mathrm{kg}^{-1} \cdot \mathrm{min}^{-1}\right)$ in only 5 . Conversely, in 9 subjects who reached the same maximal workload when taking metformin, $V \mathrm{O}_{2}$ peak was depressed by more than $1 \mathrm{~mL} \cdot \mathrm{kg}^{-1} \cdot \mathrm{min}^{-1}$ in 6 of them.

Estimated ventilatory breakpoint occurred at almost exactly the same $V \mathrm{O}_{2}$ in both conditions (data not shown). Because $\mathrm{VO}_{2}$ peak was lower with metformin, estimated VBP occurred at a slightly higher $\% V \mathrm{O}_{2 \text { peak }}$ with metformin (Table 2 ), but the difference between means was not significant.

\section{Discussion}

\section{Summary of results}

There was a significant reduction in maximal aerobic capacity when healthy, normal-weight subjects were tested while treated with a typical clinical dose of metformin as 
Fig. 1. Oxygen consumption $(a)$, heart rate $(b)$, ventilation $(c)$, respiratory exchange ratio $(d)$, and rating of perceived exertion $(e)$ over time during the maximal exercise test. Owing to different exercise durations across conditions, the full data set $(n=17)$ can only be compared during minutes $2-11$ and at the end of the test. The label "max" denotes the end of the incremental test; mean = 14.52 min for placebo and $13.92 \mathrm{~min}$ for metformin.
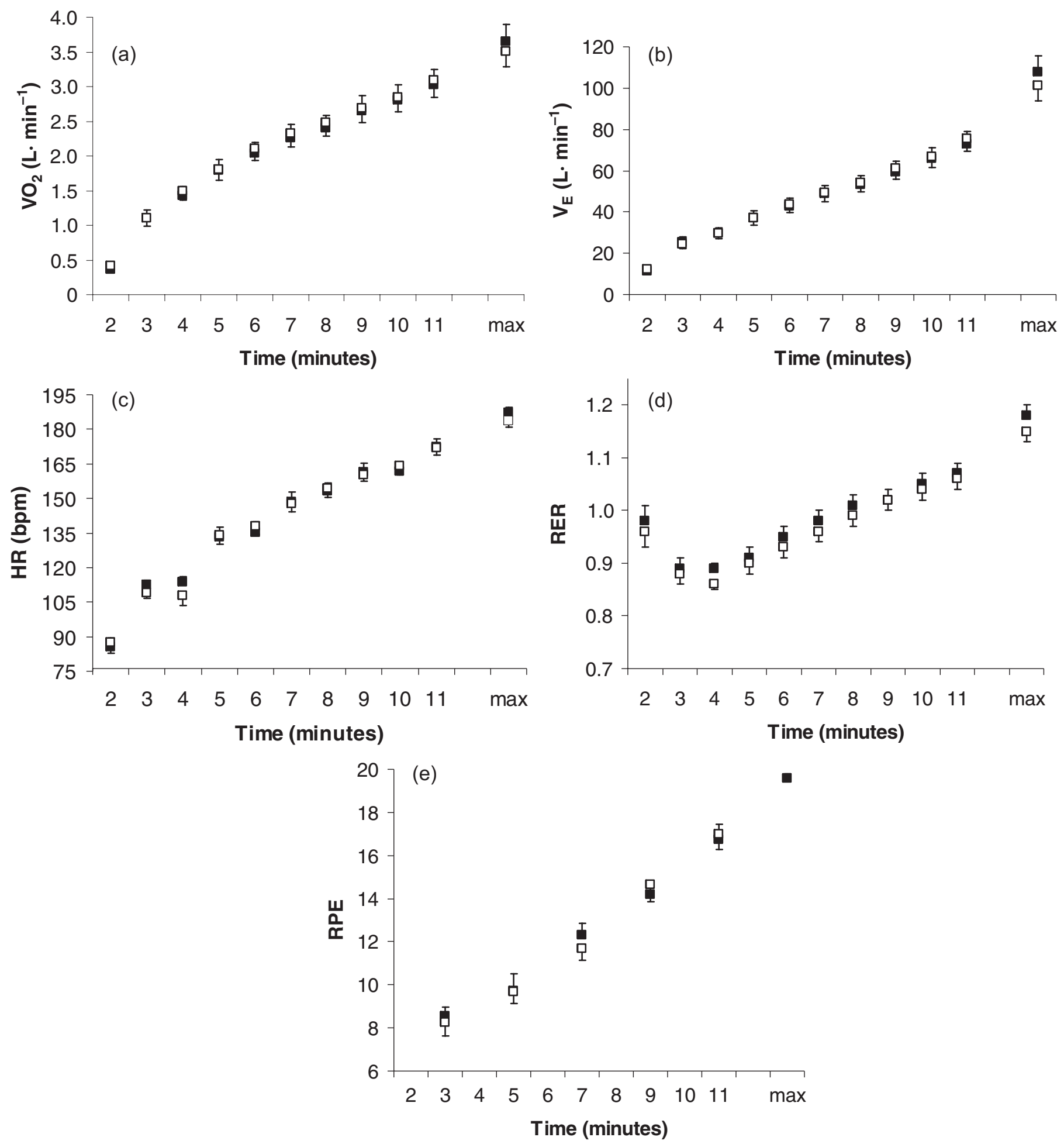

- Placebo $\square$ metformin

compared with placebo. Duration, maximal HR, maximal $V \mathrm{E}$, and maximal RER all were lower on metformin, but there were no statistically significant associations between the decline in $\mathrm{VO}_{2}$ peak and the change in any of those associated parameters. There was no effect of metformin on perceived exertion or estimated ventilatory breakpoint. 


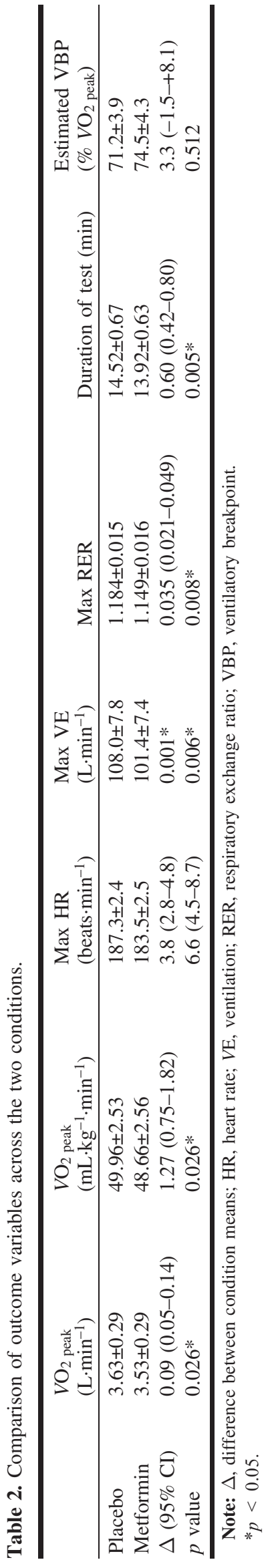

\section{Physiological relevance}

The decline in maximal cardiorespiratory capacity with metformin treatment was statistically significant but, on average, physiologically subtle. Although a $3 \%$ decline might be critical to the performance of an elite endurance athlete, it is unlikely to be of concern to the individual doing recreational physical activity to enhance health. Some individuals responded more robustly to the metformin treatment, however, with declines in $V \mathrm{O}_{2}$ peak of up to $10 \%$. A decline of that magnitude can be the difference between exercising below or above the lactate threshold, perceived exertion would be noticeably higher, and time to fatigue would be reduced. The real-world impact of metformin treatment on exercise capacity will depend on how the effects manifest over time. The antihyperglycemic effects of metformin manifest quickly and longer-term treatment does not confer increasing benefits (although metformin-associated weight loss can potentiate the direct effects). If the metformin effect on cardiorespiratory capacity we observed is transient, there may be no impairments that last beyond the first week. Conversely, if the impact of metformin on cardiorespiratory fitness is maintained or potentiated with longer-term treatment, exercise capacity could be impacted more severely. Educated speculation would be aided by understanding how metformin caused the decline in $V \mathrm{O}_{2}$ peak observed in the present study.

\section{Mechanisms}

All of the associated outcomes (maximal HR, VE, test duration, etc.) declined similarly, suggesting that individuals simply did not exercise "to their maximum" when treated with metformin. However, there was no difference between conditions in the final workload attained. Furthermore, there were no associations between exercise duration and any of the other outcomes. Lastly, maximal HR, VE, and exercise duration were not different in the individuals who had a large decline in $V \mathrm{O}_{2}$ peak with metformin (decline in $V \mathrm{O}_{2}$ peak $>1.5 \mathrm{~mL} \cdot \mathrm{kg}^{-1} \cdot \mathrm{min}^{-1}$ ) vs. those who did not (decline $<0.5 \mathrm{~mL} \cdot \mathrm{kg}^{-1} \cdot \mathrm{min}^{-1}$ ). To illustrate the point, the individual with the largest absolute decline in $V \mathrm{O}_{2}$ peak $\left(-6.5 \mathrm{~mL} \cdot \mathrm{kg}^{-1} \cdot \mathrm{min}^{-1}\right)$ had the same exercise duration and reached the same maximal workload on both tests. Conversely, the person with the largest decline in duration (placebo, $17.27 \mathrm{~min}$; metformin, $15.50 \mathrm{~min}$.) had no change in $V \mathrm{O}_{2}$ peak.

There are several potential explanations for the finding that metformin had a slight lowering effect on $\mathrm{VO}_{2}$ peak, $\mathrm{HR}$, $V E$, and RER. According to several studies, all performed using in vitro cell systems, metformin could impair $V \mathrm{O}_{2}$ peak by inhibiting the mitochondrial electron transport system (Batandier et al. 2006; El-Mir et al. 2000; Guigas et al. 2004; Leverve et al. 2003; Owen et al. 2000). The inhibition has been observed in skeletal muscle (Brunmair et al. 2004), isolated liver (Batandier et al. 2006; El-Mir et al. 2000; Leverve et al. 2003; Owen et al. 2000,) and tumor cells (Guigas et al. 2004). Effects of metformin on skeletal muscle and (or) cardiac tissue have not been studied to date. In liver cells, oxidation of malate or aspartate, but not succinate, is impaired, implying that inhibition of mitochondrial respiration is specific to complex 1 (Owen et al. 2000). In one study, metformin lessened production of reactive 
oxygen species by reverse electron transport (Batandier et al. 2006). Researchers have speculated that the inhibition of complex I may not be a pharmacological "side effect", but is instead central to the (currently still unclear) metformin mechanism of action (Leverve et al. 2003; Owen et al. 2000). Inhibition of complex I by metformin in skeletal muscle could constrain oxygen extraction (manifested as a smaller arterial-venous difference in the partial pressure of $\mathrm{O}_{2}\left(\mathrm{ppO}_{2}\right)$ ) rather than oxygen delivery (cardiac output). If the inhibition were also present in cardiac muscle then delivery could also be constrained. There were no associations between the changes in $V \mathrm{O}_{2}$ peak and maximal $\mathrm{HR}$ or $V \mathrm{E}$; even if there were, these gross measurements are inadequate to determine whether $V \mathrm{O}_{2}$ peak declines because of limitations on oxygen delivery or extraction. Without assessing cardiac output or mitochondrial $\mathrm{ppO}_{2}$, whether lower maximal $\mathrm{HR}$ and $V \mathrm{E}$ impair $V \mathrm{O}_{2}$ peak or are a result of the lower $V \mathrm{O}_{2 \text { peak }}$ cannot be determined.

Inhibition of complex I would also be expected to constrain oxidation of TCA cycle-derived reducing equivalents, restrict oxidative metabolism of pyruvate and acetyl CoA, and increase reliance on glycolytic metabolism to lactate. Blood lactate was not measured in the present study, but the lactate breakpoint can be estimated (although not necessarily causally related) from the ventilatory breakpoint, the inflection point where ventilation rises more steeply than oxygen consumption. Again, there was no difference in the ventilatory breakpoint, suggesting that the balance between oxidative and non-oxidative metabolism was not changed in response to metformin.

\section{Research and clinical implications}

Although the subtle decrements in $V \mathrm{O}_{2}$ peak attributable to metformin are unlikely to have important clinical relevance, they are germane to study designs that involve exercise and metformin treatment. Exercise intensity is usually based on a percentage of $\mathrm{VO}_{2}$ peak (Braun et al. 2004; Goodpaster et al. 2002; Houmard et al. 2004; Musi and Goodyear 2006), therefore researchers need to measure $V_{2}$ peak while the subject is on metformin or risk incorrectly setting the exercise intensity during the metformin treatment intervention. Metformin is prescribed to manage hyperglycemia in individuals with diabetes and prophylactically to delay the transition to diabetes for individuals with elevated fasting glucose (De Lusignan et al. 2005; Jadhav et al. 2006). The healthy subjects used in the present study limits the application of the results to clinical populations. Healthy individuals were tested to avoid the complication of underlying mitochondrial myopathy or the confounding variable of hyperglycemia. Whether maximal oxygen consumption would change to a greater or lesser extent in people with diabetes or insulin resistance is difficult to predict. In general, cardiorespiratory fitness is lower in those individuals compared to the men and women tested in the current study (Regensteiner et al. 1998), but we saw no effects of baseline fitness on the magnitude of the observed differences. When matched for other confounding variables (e.g., body fat, $V \mathrm{O}_{2}$ peak, habitual physical activity) blood glucose uptake during exercise is the same between insulin-resistant and insulin-sensitive individuals (Braun et al. 2004). To determine whether the decrement in $V_{2}$ peak observed in non- diabetic individuals will be exaggerated or attenuated in those with insulin resistance or diabetes will require explicitly testing the effects of metformin on aerobic capacity in those individuals. The observation that $V \mathrm{O}_{2}, V \mathrm{E}, \mathrm{HR}$, and RER were not affected by metformin at submaximal workloads has clear practical relevance. The results imply that exercise capacity is only affected at or near maximal workloads. Therefore, it is unlikely that individuals would experience any impairment in exercise tolerance at the exercise intensities experienced by the great majority of recreationally active individuals.

\section{Acknowledgements}

Thanks to Rebecca Hasson, Steven Malin, Kaila Holtz, and Kirsten Granados for helpful discussion. The authors also thank the subjects for their dedicated participation in the study. Supported by American Diabetes Association Junior Faculty grant No. 7-04-JF-10.

\section{References}

Anderson, D.C., Jr. 2005. Pharmacologic prevention or delay of type 2 diabetes mellitus. Ann. Pharmacother. 39: 102-109. PMID:15562143.

Batandier, C., Guigas, B., Detaille, D., El-Mir, M.Y., Fontaine, E., Rigoulet, M., and Leverve, X.M. 2006. The ROS production induced by a reverse-electron flux at respirator-chain complex 1 is hampered by metformin. J. Bioenerg. Biomembr. 38: 33-42. doi:10.1007/s10863-006-9003-8. PMID:16732470.

Bethel, M.A., and Califf, R.M. 2007. Role of lifestyle and oral anti-diabetic agents to prevent type 2 diabetes mellitus and cardiovascular disease. Am. J. Cardiol. 99: 726-731. doi:10.1016/j. amjcard.2006.09.122. PMID:17317381.

Braun, B., Sharoff, C.G., Chipkin, S.R., and Beaudoin, F.L. 2004. Effects of insulin resistance on substrate utilization during exercise in overweight women. J. Appl. Physiol. 97: 991-997. doi:10.1152/japplphysiol.00231.2004. PMID:15133003.

BroPaitienë, J., and Jakumaitë, V. 2002. Ventilatory response to workload in patients with chronic heart failure. Biomedicine, 2: $37-40$.

Brunmair, B., Staniek, K., Gras, F., Scharf, N., Althaym, A., Clara, R., et al. 2004. Thiazolidinediones, like metformin, inhibit respiratory complex I: a common mechanism contributing to their antidiabetic actions? Diabetes, 53: 1052-1059. doi:10.2337/ diabetes.53.4.1052. PMID:15047621.

Cohen-Solal, A., Zannad, F., Kayanakis, F.M., Gueret, P., Aupetit, J.F., and Kolsky, H. 1991. Multicentre study of determination of peak oxygen uptake and ventilatory threshold during bicycle exercise in chronic heart failure. Comparison of graphical methods, interobserver variability and influence of the exercise protocol. The $\mathrm{VO}_{2}$ French Study Group. Eur. Heart J. 12: 10551063. PMID: 1782929.

Dasgupta, K., Grover, S.A., Da Costa, D., Lowenstyn, I., Yale, J.F., and Rahme, E. 2006. Impact of modified glucose target and exercise interventions on vascular risk factors. Diabetes Res. Clin. Pract. 72: 53-60. doi:10.1016/j.diabres.2005.09.010. PMID: 16256242

De Lusignan, S., Sismanidis, D., Carey, I.M., DeWilde, S., Richards, N., and Cooke, D.G. 2005. Trends in the prevalence and management of diagnosed type 2 diabetes 1994-2001 in England and Wales. BMC Fam. Pract. 6: 13-20. doi:10.1186/14712296-6-13. PMID:15784133.

Driscoll, S.D., Meininger, G.E., Lareau, M.T., Dolan, S.E., Killilea, 
K.M., Hadigan, C.M., et al. 2004. Effects of exercise training and metformin on body composition and cardiovascular indices in HIV-infected patients. AIDS, 18: 465-473. doi:10.1097/ 00002030-200402200-00013. PMID:15090799.

El-Mir, M.Y., Noguiera, V., Fontaine, E., Rigoulet, M., and Leverve, X. 2000. Dimethylguanide inhibits cell respiration via an indirect effect targeted on the respiratory chain complex 1. J. Biol. Chem. 275: 223-228. doi:10.1074/jbc.275.1.223. PMID: 10617608.

Goodpaster, B.H., Wolfe, R.R., and Kelley, D.E. 2002. Effects of obesity on substrate utilization during exercise. Obes. Res. 10: 575-584. PMID: 12105277.

Guigas, B., Detaille, D., Chauvin, C., Batandier, C., De Oliviera, F., Fontaine, E., and Leverve, X. 2004. Metformin inhibits mitochondrial permeability transition and cell death: a pharmacological in vitro study. Biochem. J. 382: 877-884. doi:10.1042/ BJ20040885. PMID:15175014.

Hallsten, K., Virtanen, K.A., Lonnqvist, F., Sipila, H., Oksanen, A., Viljanene, A., et al. 2002. Rosiglitazone but not metformin enhances insulin- and exercise-stimulated skeletal muscle glucose uptake in patients with newly diagnosed type 2 diabetes. Diabetes, 51: 3479-3485. doi:10.2337/diabetes.51.12.3479. PMID: 12453903.

Hamman, R.F., Wing, R.R., Edelstein, S.L., Lachin, J.M., Bray, G.A., Delahanty, L., et al. 2006. Effect of weight loss with lifestyle intervention on risk of diabetes. Diabetes Care, 29: 21022107. doi:10.2337/dc06-0560. PMID:16936160.

Houmard, J.A., Tanner, C.J., Slentz, C.A., Duscha, B.D., McCartney, J.S., and Krauss, W.E. 2004. Effect of the volume and intensity of exercise training on insulin sensitivity. J. Appl. Physiol. 96: 101-106. doi:10.1152/japplphysiol.00707.2003. PMID:12972442.

Jadhav, S., Ferrell, W., Greer, I.A., Petrie, J.R., Cobbe, S.M., and Sattar, N. 2006. Effects of metformin on microvascular function and exercise tolerance in women with angina and normal coronary arteries; a randomized, double-blind, placebo-controlled study. J. Am. Coll. Cardiol. 48: 956-963. doi:10.1016/j.jacc. 2006.04.088. PMID:16949486.

Knowler, W.C., Barrett-Connor, E., Fowler, S.E., Hamman, R.F., Lachin, J.M., Walker, E.A., and Nathan, D.M. 2002. Reduction in the incidence of type 2 diabetes with lifestyle intervention or metformin. N. Engl. J. Med. 346: 393-403. doi:10.1056/ NEJMoa012512. PMID:11832527.

Kriska, A.M., Edelstein, S.L., Hamman, R.F., Otto, A., Bray, G.A., Mayer-Davis, E.J., et al. 2006. Physical activity in individuals at risk for diabetes: Diabetes Prevention Program. Med. Sci. Sports Exerc. 38: 826-832. doi:10.1249/01.mss.0000218138.91812.f9. PMID:16672833.

Leverve, X.M., Guigas, B., Detaille, D., Batandier, C., Koceir, E.A., Chauvin, C., et al. 2003. Mitochondrial metabolism and type-2 diabetes: a specific target of metformin. Diabetes Metab. 29: 6S88-94. PMID:14502105.

Lowell, B.B., and Shulman, G.I. 2005. Mitochondrial function and type 2 diabetes. Science, 307: 384-387.

Manson, J.E., and Spelsberg, A. 1994. Primary prevention of noninsulin-dependent diabetes mellitus. Am. J. Prev. Med. 10: 172184. PMID:7917445.

Matthaei, S., Stumvoll, M., Kellerer, M., and Haring, H.-U. 2000. Pathophysiology and pharmacological treatment of insulin resistance. Endocr. Rev. 21: 585-618. doi:10.1210/er.21.6.585. PMID:11133066.

Musi, N., and Goodyear, L.J. 2006. Insulin resistance and improvements in signal transduction. Endocrine, 29: 73-80. doi:10.1385/ ENDO:29:1:73. PMID:16622294.

Orchard, T.J., Temprosa, M., Goldberg, R., Haffner, S., Ratner, R., Marcovina, S., and Fowler, S. 2005. The effect of metformin and intensive lifestyle intervention on the metabolic syndrome: the Diabetes Prevention Program randomized trial. Ann. Intern. Med. 142: 611-619. PMID:15838067.

Owen, M.R., Doran, E., and Halestrap, A.P. 2000. Evidence that metformin exerts its anti-diabetic effects through inhibition of complex 1 of the mitochondrial respiratory chain. Biochem. J. 348: 607-614. doi:10.1042/0264-6021:3480607. PMID:10839993.

Pan, X.R., Li, G.W., Hu, Y.H., Wang, J.X., Yang, W.Y., An, Z.X., et al. 1997. Effects of diet and exercise in preventing NIDDM in people with impaired glucose tolerance. The Da Qing IGT and Diabetes Study. Diabetes Care, 20: 537-544. doi:10.2337/ diacare.20.4.537. PMID:9096977.

Regensteiner, J.G., Bauer, T.A., Reusch, J.E., Brandenburg, S.L., Sippel, J.M., Vogelsong, A.M., et al. 1998. Abnormal oxygen uptake kinetic responses in women with type II diabetes mellitus. J. Appl. Physiol. 85: 310-317. PMID:9655791.

Ritov, V.B., Menshikova, E.V., He, J., Ferrell, R.E., Goodpaster, B.H., and Kelley, D.E. 2005. Deficiency of subsarcolemmal mitochondria in obesity and type 2 diabetes. Diabetes, 54: 8-14. doi:10.2337/diabetes.54.1.8. PMID:15616005.

Smith, A.C., Mullen, K.L., Junkin, K.A., Nickerson, J., Chabowski, A., Bonen, A., and Dyck, D.J. 2007. Metformin and exercise reduce muscle FAT/CD36 and lipid accumulation and blunt the progression of high-fat diet induced hyperglycemia. Am. J. Physiol. Endocrinol. Metab. 293: E172-E181. doi:10.1152/ajpendo. 00677.2006. PMID:17374701.

Tang, T., and Reed, M.J. 2001. Exercise adds to metformin and acarbose efficacy in db/db mice. Metabolism, 50: 1049-1053. doi:10.1053/meta.2001.25596. PMID:11555837.

Tuomilehto, J., Lindstrom, J., Eriksson, J.G., Valle, T.T., Hamalainen, H., Ilanne-Parikka, P., et al. 2001. Prevention of type 2 diabetes mellitus by changes in lifestyle among subjects with impaired glucose tolerance. N. Engl. J. Med. 344: 1343-1350. doi:10.1056/NEJM200105033441801. PMID:11333990. 